\title{
SOLAR AND AURORAL ACTIVITIES DURING THE 17th \\ CENTURY
}

\author{
J.P. LEGRAND \\ CNRS, 4 av. de Neptune, \\ F-94107 Saint-Maur Cedex, France \\ M. LE GOFF \\ CNRS, Lab. de Geomagnetisme, 4 av. de Neptune, \\ F-94107 Saint-Maur Cedex, France \\ C. MAZAUDIER \\ CRPE, 4 av. de Neptune, \\ F-94107 Saint-Maur Cedex, France \\ and \\ W. SCHRÖDER \\ Hechelstr. 8, \\ D-2820 Bremen-Rönnebeck, Germany
}

The dark spots on the solar disk, some of them are visible with the naked eye, and the aurorae, especially those strectching down to the tropics, are the best visible manifestations of the solar activity. Since more than one century, we know that this activity follows a regular periodic cycle of 11-years (Heinrich Schwabe 1844), but with an intensity, which is sufficiently variable, to speak of "small" and "large" solar cycles.

Actually, we observe a serie of large cycles, on the contrary at the end of the 17 th century this activity has been weak during several decades. This was just the epoch of rapid progress of the instrumental astronomy in Europe.

This period of weak intensity, which attracted the attention of the German astronomer G.F.W. Spörer $(1822-1895)$ as early as 1890 , is known by the name "Maunder-minimum" (cf. Eddy, 1976).

What do we really know about this period? Are the used tools sufficiently accurate? What can we bring out analysing all records from the begin of the 17 th century?

The main results are that a) sunspots have been observed more frequently than often reported in earlier papers. b) auroras have been observed in Middle Europe continuously. Because they are indicators of solar-geomagnetic activity it follows that no unusual variability in solar or geomagnetic activity is indicated.

\section{References}

Eddy, J.A.: 1976, Science 192, 1189.

Legrand, J.P., Goff, M.Le, Mazaudier: 1990, in Advances in Geosciences ed. by W. Schröder, Bremen-Rönnebeck, 15.

Schröder, W.: 1984, in Das Phänomen des Polarlichts, (Auroral Borealis), Wiss. Buchgesellschaft, Darmstadt.

Schröder, W.: 1992, J. Geomag. Geoelectr. 44, 119.

Schwabe, H.: 1844, Astron. Nachrichten 21, 233. 